\title{
Efektivitas Program Pelayanan Berkelanjutan Inseminasi Buatan dan Gangguan Reproduksi Sapi (Pelan Itu Bagus) di Kabupaten Pinrang
}

\section{The Effectiveness of the Program Sustained Artificial Insemination and Disorders of Reproductive in Cows (Pelan Itu Bagus) in Pinrang Regency}

\author{
M. Rahman ${ }^{1 *}$ dan A. I. Sari ${ }^{2}$ \\ ${ }^{1}$ Program Studi Agroteknologi, Fakultas Ilmu Pertanian, STIP YAPI BONE - Indonesia \\ ${ }^{2}$ Dinas Peternakan dan Perkebunan, Kabupaten Pinrang - Indonesia \\ *Corresponding E-mail: mahyuddinunhas@yahoo.co.id \\ (Diterima: 23 November 2020; Disetujui: 29 April 2021)
}

\begin{abstract}
ABSTRAK
Program Pelayanan Berkelanjutan Inseminasi Buatan dan Gangguan Reproduksi Sapi (Pelan Itu Bagus) merupakan salah satu terobosan inovasi Dinas Peternakan dan Perkebunan Kabupaten Pinrang dalam upaya menopang keberhasilan program Upaya Khusus Sapi Indukan Wajib Bunting (Upsus Siwab). Penelitian ini bertujuan untuk melihat peranan dan tingkat keberhasilan program Pelan Itu Bagus. Penelitian ini dirancang sebagai peneltian deskriktif (Deskriptif Research) yaitu untuk mendeskripsikan peranan dan tingkat keberhasilan program Pelan Itu Bagus. Penelitian ini dilaksanakan di Kabupaten Pinrang dengan jumlah populasi sebanyak 793 Peternak. Besaran sampel ditentukan dengan menggunakan pendekatan metode Slovin yaitu sebanyak 266 Peternak. Hasil penelitian menunjukkan bahwa peranan program Pelan Itu Bagus terhadap tingkat pelayanan petugas sebanyak $48 \%$ menunjukkan frekuensi pelayanan meningkat dari 1 kali menjadi 3 kali dalam satu bulan bila dibandingkan sebelum ada program Pelan Itu Bagus hanya 1 kali dalam satu bulan. Tingkat kelahiran menunjukkan peternak mampu menghasilkan 1 ekor sapi/tahun dan meningkat sebanyak 361 ekor atau 146,7\% dari 246 ekor sebelum adanya inovasi Pelan Itu Bagus. Tingkat penyakit gangguan reproduksi menunjukkan secara keseluruan di wilayah Kabupaten Pinrang dibawah 1 kasus/tahun dan mengalami penuruan sebanyak 203 kasus atau 34,64\% dari 586 kasus sebelum adanya inovasi pelan Itu Bagus. Pendapatan peternak sapi rata-rata menunjukkan pada hasil distribusi frekuensi untuk skala usaha terendah yaitu 3 sampai 7 ekor sebesar Rp. 11.500.000 per tahun dan skala usaha tertinggi yaitu 43 sampai 47 ekor sebesar 80.500 .000 per tahun. Kesimpulan pada penelitian ini bahwa program Pelayanan Berkelanjutan Inseminasi Buatan dan Gangguan Reproduksi Sapi (Pelan Itu Bagus) di Kabupaten Pinrang dapat dikatakan efektif dan berhasil.
\end{abstract}

Kata kunci: pelayanan petugas, tingkat kelahiran, gangguan reproduksi, pendapatan

\section{ABSTRACT}

The Continuous Service Program for Artificial Insemination and Reproduction Disorders of Cows (Pelan Itu Bagus) is one of the innovations of The Pinrang District Office Stockbreeding and Farm to support the success of the Special Efforts program for cows to become pregnant (UPSUS SIWAB). This study aims to determine the role and success rate of the program Pelan Itu Bagus. This research was designed as descriptive research (Descriptive Research), namely to describe the part and success rate of Pelan Itu Bagus program. This research was conducted in Pinrang District by a population of 793 breeders. The sample size was determined using the Slovin method approach, namely as many as 266 farmers. The results showed that the role of the program Pelan Itu Bagus on the service level of officers was $48 \%$, indicating that the frequency of service increased from once to three times a month when compared to Pelan Itu Bagus program only once a month. The birth rate shows that the breeders can produce a cow in a year and an increase in 361 cows or 146.7\% from 246 cows before the innovation of Pelan Itu Bagus. The rate of reproduction disorders cow shows that overall at Pinrang District is below one case in a year and has decreased by 203 points or 34.64\% from 586 cases before the innovation of Pelan Itu Bagus. The 
average income of cattle breeders shows that the frequency distribution results for the lowest business scale are 3 to 7 heads of Rp. 11,500,000 in a year and the highest business scale 43 to 47 heads Rp. 80,500,000 in a year. The research concludes research is that the Sustainable Service program for Artificial Inseminasi and Reproduction Disorders of the Cow (Pelan Itu Bagus) in Pinrang District can be said to be effective and successful.

Keywords: officer services, birth rate, reproductive disorders, income

\section{PENDAHULUAN}

Penambahan jumlah populasi ternak khususnya sapi potong masih belum seimbang jika dibandingkan terhadap laju pertumbuhan jumlah penduduk di Indonesia. Konsekuensinya hingga pada saat ini, impor sapi potong sampai saat ini masih terus dilakukan dengan tujuan untuk memenuhi kebutuhan konsumsi daging di dalam negeri. Peternakan sapi di Indonesia secara umum dalam kondisi yang sangan memprihatinkan. Hal ini dapat dibuktikan dengan melihat produksi daging sapi di Indonesi sebanyak $78 \%$ kontribusinya berasal dari peternakan rakyat. Selisinya berasal dari impor, kemudian kurang lebih lima persen merupakan daging sapi dan $17 \%$ adalah sapi potong (Malik, 2019).

Sistem pemeliharaan ternak sapi di Indonesia masih dominan bentuk usaha secara tradisional dengan karakteristik sebagai berikut: (1) Rerata jumlah kepemilikan ternak masih sedikit; (2) Ternak sapi masih dijadikan sebagai asset atau tabungan hidup; (3) Pemeliharaan ternak sapi masih dilakukan di pemukiman yang padat penduduk atau dikandangkan di sekitar rumah; (4) Masih minimnya lahan pemeliharaan sebagai sumber pakan, sehingga peternak seringkali mencari pakan yang jauh dari kawasan kandang; (5) Peternakan sapi masih merupakan usaha turun temurun; (6) Sumber modal masih sukar didapatkan sehingga peternak mengaduh dengan sistem bagi hasil (Zakiah et al., 2017).

Pemanfaatan teknologi inseminasi buatan merupakan salah satu upaya untuk meningkatkan usaha dan populasi ternak sapi di Indonesia. Penerapan teknologi inseminasi buatan diharapkan dapat menjadi media dalam upaya meningkatkan populasi ternak sapi potong. Untuk menopang keberhasilan pembangunan peternakan di Indonesia, maka diperlukan perhatian khusus pada peternakan rakyat yang merupakan kontribusi terbesar dari peternakan di Indonesia dalam upaya pengembangannya. Meningkatkan skala kepemilikan dan mutu genetik ternak sapi potong merupakan salah satu langkah dalam peningkatan produktivitas daging. Hal tersebut bisa dilakukan dengan mengaplikasikan inovasi inseminasi buatan (IB) pada sapi potong (Amin et al., 2019).

Kabupaten Pinrang adalah suatu kabupaten yang masuk pada wilayah Propinsi Sulawesi Selatan. Letak geografis dan kekayaan sumber daya alam sangat mendukung pengembangan usaha ternak sapi. Populasi sapi Kabupaten Pinrang tahun 2020 sebanyak 27.323 ekor dan termasuk wilayah sentra pengembangan sapi di Propinsi Sulawesi Selatan (BPS, 2020).

Perkembangan populasi sapi di Kabupaten Pinrang sampai saat ini belum maksimal, penyebabnya adalah minimnya pengetahuan peternak terkait manajemen pemeliharaan ternak sapi yang baik. Sebagian besar peternak dalam menjalankan usaha peternakan sapi bukan sebagai usaha pokok melainkan sebagai usaha sambilan. Umumnya indukan ternak sapi potong hanya bisa menghasilkan anak sekitar 2 atau 3 ekor selama 5 tahun pemeliharaan, hal ini menunjukkan nilai ekonomis sangat rendah atau tidak layak dari segi budidaya yang seharusnya sapi betina bisa menghasilkan 1 ekor/tahun. hal ini merujuk pada Prasojo et al. (2010) menyatakan bahwa lama kebuntingan adalah 284 hari atau kurang lebih 9 bulan.

Kawin Suntik atau Inseminasi Buatan 
(IB) merupakan suatu kegiatan yang ada didalam program upsus siwab. Selain itu inseminasi buatan juga merupakan sebuah inovasi dalam penerapan teknologi budidaya sapi potong dalam upaya peningkatan populasi ternak serta perbaikan mutu genetic ternak. Inseminasi Buatan adalah usaha memasukkan semen atau sperma melalui alat kelamin induk betina yang birahi dengan menggunakan alat inseminasi agar supaya ternak bisa bunting (Dirjen Peternakan dan Kesehatan Hewan, 2012). Namun disisi lain terdapat kendala dalam keberhasilan inseminasi buatan. Salah satu faktor yang menjadi penyebab peningkatan populasi ternak sapi potong terhambat yaitu dengan adanya kelainan pada organ reproduksi. Penyakit ini dapat mengakibatkan rendahnya kemampuan reproduksi untuk menghasilkan anak. Kurang terkontrolnya sistem perkawinan alam, penyebab utama dari penyakit ini. Sapi yang dipelihara dengan sistem dilepas berpeluang besar terhadap penularan penyakit gangguan reproduksi (Armelia, 2019).

Program Pelayanan Secara Berkelanjutan Inseminasi Buatan dan Gangguan Reproduksi Sapi (Pelan Itu Bagus) merupakan sebuah terobosan program yang disusun oleh Pemerintah Kabupaten Pinrang dengan tujuan memberikan pelayanan selama 21 hari dalam satu kelompok sesuai dengan siklus birahi sapi yaitu 21 hari. Pelayanan ini dapat memberikan pemahaman kepada masyarakat tentang manfaat teknologi inseminasi buatan dan kelainan pada organ reproduksi sapi serta perubahan mindset terhadap pemeliharaan sapi yang baik. Pelayanan selama 21 hari yang dilaksanakan para petugas teknis Dinas Peternakan dan Perkebunan yang tergabung dalam tim teknis program upsus siwab yang meliputi inseminasi buatan, pemeriksaan kebuntingan, Asisten Teknis Reproduksi (ATR), dan sosialisasi melalui kegiatan penyuluhan tentang manajemen usaha peternakan yang baik (Dinas Peternakan dan Perkebunan, 2017).

Inovasi Pelan Itu Bagus sudah mulai dilakukan sejak tahun 2018 hingga sekarang dan optimal pada tahun 2019. Lahirnya inovasi tersebut untuk menunjang keberhasilan program upsus siwab di Kabupaten Pinrang yang merupakan salah satu wilayah yang potensial pengembangan sentral produksi sapi potong di Provinsi Sulawesi Selatan. Wilayah tersebut sangatlah strategis dalam upaya pengembangan ternak sapi potong dengan daya dukung sumber daya alam yang meliputi ketersediaan lahan pengembalaan ternak, kondisi iklim, dan jumlah populasi ada di setiap wilayah kecamatan. Sejalan dengan lahirnya inovasi tersebut belum dilakukan kajian terhadap inovasi tersebut. Dengan demikian perlu dilakukan kajian terobosan inovasi tersebut untuk melihat kontribusi inovasi pelan itu bagus. Selain itu, pada penelitian ini juga diharapkan dapat menjelaskan gambaran keunggulan dan kelemahan dalam pelaksanan program tersebut.

Berdasarkan uraian diatas, dapat dilihat bahwa Kabupaten Pinrang memiliki potensi pengembangan populasi sapi potong dengan strategi penyusunan terobosan inovasi Pelan Itu Bagus maka peneliti sangat tertarik melihat "Efektivitas Program Pelayanan Berkelanjutan Inseminasi Buatan dan Gangguan Reproduksi Sapi (Pelan Itu Bagus) di Kabupaten Pinrang”.

\section{METODE}

\section{Desain Penelitian}

Penelitian ini dirancang sebagai penelitian deskritif (Deskriptif Research) yang merupakan suatu desain penelitian untuk menggambarkan atau mendeskripsikan program Pelayanan Secara Berkelanjutan Inseminasi Buatan dan Gangguan Reproduksi Sapi (Pelan Itu Bagus) dengan cara wawancara dengan menggunakan kuisioner. Adapun variabel dalam penelitian ini yaitu program Pelan Itu Bagus. Kemudian sub variabel dalam penelitian yaitu peranan program dan tingkat keberhasilan program. Indikator pengukuran peranan program yaitu Tingkat Pelayanan, 
Tabel 1. Tingkat Pelayanan Petugas

\begin{tabular}{lcc}
\hline Jumlah Pelayanan (Bulan) & Jumlah Responden (orang) & Persentase (\%) \\
\hline 4 Kali & 62 & 23 \\
3 Kali & 126 & 48 \\
2 Kali & 46 & 17 \\
1 Kali & 32 & 12 \\
Tidak Pernah & 0 & 0 \\
\hline
\end{tabular}

Sumber: Data primer, 2020.

Tingkat kelahiran, Tingkat Gangguan Reproduksi dan Pendapatan Peternak. Sedangkan tingkat keberhasilan indikatornya yaitu Calving Interval (CI), Conception Rate (CR), dan Service Per Conception (S/C).

\section{Waktu dan Lokasi Penelitian}

Penelitian dilaksanakan pada Bulan Mei sampai Agustus Tahun 2020. Penentuan lokasi penelitian dilakukan secara sengaja (Purposive), yaitu pengambilan daerah Kabupaten Pinrang sebagai lokasi penelitian dengan mepertimbangkan bahwa daerah tersebut terdapat terobosan program Pelayanan Secara Berkelanjutan Inseminasi Buatan dan Gangguan Reproduksi Sapi (Pelan Itu Bagus).

\section{Populasi dan Sampel}

Populasi pada penelitian ini adalah jumlah peternak yang memiliki sapi sebagai aseptor Inseminasi Buatan yang menjadi target penerapan inovasi Pelan Itu Bagus di Kabupaten Pinrang pada Tahun 2019 sebanyak 793 peternak. Teknik penentuan besaran sampel pada penelitian ini menggunakan pendekatan rumus Slovin yaitu penentuan besaran sampel dengan melalui tingkat kesalahan (Umar, 2001). sehingga besarnya sampel dalam penelitian ini yaitu 266 Peternak dengan skala usaha paling sedikit 3 ekor dan paling banyak 47 ekor sapi. Pengambilan sampel dilakukan dengan metode simple random sampling.

\section{Sumber Data}

Jenis data yang digunakan dalam penelitian ini yaitu data kuantitatif merupakan suatu data yang bersifat bilangan atau angkaangka yang mempunyai hubungan dengan penelitian, seperti jumlah peternak yang memiliki sapi sebagai aseptor inseminasi buatan, populasi sapi, tingkat kelahiran, kasus penyakit reproduksi serta pendapatan peternak. Data yang disjikan pada penelitian ini adalah data kuantitatif dengan penskalaan yaitu menggunakan skala rasio seperti keadaan skala usaha peternak, tingkat pelayanan, dan pendapatan peternak. Adapun sumber data yang digunakan pada penelitian ini adalah data primer dan sekunder. Data primer yaitu data yang bersumber dari observasi yang dilakukan dalam bentuk interview atau wawancara langsung dengan menggunakan bantuan kuesioner yang meliputi data tingkat pelayanan, pendapatan, kelahiran, gangguan reproduksi dan tingkat keberhasilan. Sedangkan data sekunder yaitu data yang di dapatkan dari berbagai sumber kepustakaan yang meliputi data populasi ternak dan jumlah peternak sapi.

\section{Teknik Pengumpulan Data}

Pada Penelitian ini, teknik pengumpulan data yaitu dengan cara wawancara langsung atau wawancara secara mendalam (Indepth Interview) menggunakan alat bantu berupa kuesioner yang berisi tentang profil peternak, tingkat pelayanan, dan pendapatan. Selain itu, pengumpulan data juga dilakukan dengan kajian data program yang diperoleh diperoleh dari instansi pemerintah khususnya Dinas Peternakan dan Perkebunan melalui aplikasi Isikhnas yaitu data berupa jumlah kelahiran dan tingkat kasus gangguan reproduksi.

\section{Analisis Data}

Analisis data yang digunakan dalam menyelesaikan rumusan masalah pada 
Tabel 2. Tingkat kelahiran Berdasarkan Wilayah di Kabupaten Pinrang

\begin{tabular}{lcc}
\hline Kecamatan & Jumlah Responden (orang) & Jumlah Kelahiran IB (ekor) \\
\hline Batulappa & 11 & 14 \\
Cempa & 2 & 3 \\
Duampanua & 28 & 32 \\
Lanrisang & 9 & 12 \\
Lembang & 46 & 67 \\
Mattiro Bulu & 35 & 42 \\
Mattiro Sompe & 3 & 5 \\
Paleteang & 3 & 3 \\
Patampanua & 74 & 90 \\
Suppa & 21 & 25 \\
Tiroang & 28 & 33 \\
Watang Sawitto & 6 & 9 \\
\hline Total & 266 & 335 \\
\hline
\end{tabular}

Sumber: Data primer, 2020

penelitian efektifitas program Pelayanan Berkelanjutan Inseminasi Buatan dan Gangguan Reproduksi Sapi (Pelan Itu Bagus) yaitu menggunakan metode analisis statistik dengan menggambarkan jumlah dan persentase tiap wilayah di Kabupaten Pinrang yang diuraikan secara deskriktif. Semua data dan informasi yang didapat, selanjutanya ditabulasikan sesuai dengan kriteria datanya kemudian ditentukan nilai rataan dan standar deviasi dengan menggunakan Software Microsoft Office Excel.

\section{HASIL DAN PEMBAHASAN}

Peranan program Pelan Itu Bagus terhadap program Upsus Siwab dapat dilihat dari tingkat pelayanan petugas, peningkatan populasi usaha peternak, tingkat kasus gangguan reproduksi dan peningkatan pendapatan peternak.

\section{Pelayanan Petugas}

Pelayanan petugas merupakan kegiatan rutin yang dilakukan petugas teknis Dinas Peternakan dan Perkebunan dalam memberikan pelayanan secara langsung kepada peternak. Adapun beberapa bentuk pelayanan petugas yaitu diantaranya pelayanan inseminasi buatan, pemeriksaan kebuntingan, penangan gangguan reproduksi (Gangrep) serta kesehatan hewan. Pelayanan merupakan salah satu indikator keberhasilan program Pelan Itu Bagus di Kabupaten Pinrang.

Indikator tingkat pelayanan sebanyak 3 kali merupakan jumlah pelayanan yang tertinggi dengan tingkat persentase sebanyak 48 persen, begitupula sebaliknya indikator pelayanan terendah adalah 1 kali pelayanan dengan tingkat persentasi sebanyak 12 persen (Tabel 1). Hal ini menunjukkan bahwa pelayanan petugas Dinas Peternakan dan Perkebunan dalam satu bulan petugas mampu melakukan pelayanan sebanyak 4 kali. Sebelum adanya inovasi Pelan Itu Bagus pada Tahun 2017, data menunjukkan bahwa tingkat pelayanan petugas rata-rata cuma 1 kali dalam sebulan, dilihat dari data rekapan Isikhnas Dinas Peternakan dan Perkebunan, pelayanan hanya diberikan pada saat melakukan inseminasi buatan. Dengan demikian, dapat di simpulkan bahwa kehadiran inovasi Pelan Itu Bagus memberikan dampak terhadap tingkat pelayanan petugas di Dinas Peternakan dan Perkebunan Kabupaten Pinrang. Bentuk 
Tabel 3. Tingkat Penyakit Reproduksi Berdasarkan Wilayah di Kabupaten Pinrang

\begin{tabular}{lcc}
\hline Kecamatan & Jumlah Responden (orang) & Jumlah Kasus (ekor) \\
\hline Batulappa & 11 & 2 \\
Cempa & 2 & 0 \\
Duampanua & 28 & 8 \\
Lanrisang & 9 & 2 \\
Lembang & 46 & 12 \\
Mattiro Bulu & 35 & 10 \\
Mattiro Sompe & 3 & 1 \\
Paleteang & 3 & 0 \\
Patampanua & 74 & 19 \\
Suppa & 21 & 7 \\
Tiroang & 28 & 5 \\
Watang Sawitto & 6 & 2 \\
\hline Total & 266 & 68 \\
\hline
\end{tabular}

Sumber: Data primer, 2020.

pelayanan petugas adalah melakukan pengontrolan birahi agar supaya tidak terlewatkan. Selain itu, melakukan pelayanan lainnya seperti pengendalian penyakit, pemeriksaan kebuntingan, dan penanganan kelahiran. Hal ini dapat dibuktikan dengan peningkatan jumlah kelahiran mencapai 1.360 ekor (Dinas Peternakan dan Perkebunan, 2019).

\section{Tingkat Kelahiran}

Peningkatan populasi merupakan bertambahnya jumlah populasi usaha peternak secara signifikan yang dapat dilihat dari peningkatan skala usaha. Peningkatan populasi juga salah satu tujuan utama program inovasi pelan itu bagus untuk menopang keberhasilan UPSUS SIWAB. Lebih lanjut, Rusdiana dan Soeharsono (2018) menerangkan bahwa dalam program UPSUS SIWAB terdapat beberapa kegiatan, dua kegiatan diantaranya merupakan program utama yaitu inseminasi buatan dan kawin alam dengan tujuan upaya peningkatan populasi sapi potong.

Jumlah kelahiran pada tiap wilayah kabupaten pinrang setiap peternak sapi potong mampu menghasilkan 1 ekor dalam satu tahun (Tabel 2). Dengan demikian dapat dikatakan bahwa tujuan program pelan itu bagus dapat dikatakan berhasil. Data Isikhnas Dinas Peternakan dan Perkebunan (2019), menunjukkan kelahiraan inseminasi buatan maupun kawin alam mengalami kenaikan yang signifikan. Sebelum ada inovasi, jumlah kelahiran sebanyak 633 ekor pada tahun 2017. Sebanyak 246 ekor lahir melalui program inseminasi buatan dengan tingkat persentase sebesar 38,86\% sedangkan 387 ekor lahir melalui kawin alam dengan tingkat persentase sebesar $61,14 \%$. Tingkat kelahiran paling dominan melalui kawin alam, sehingga dapat kita simpulkan bahwa penerapan teknologi inseminasi buatan belum secara maksimal efektif. Setelah ada inovasi Pelan Itu Bagus yang dimulai pada Tahun 2018, jumlah kelahiran sebanyak 1.360 ekor pada Tahun 2019. Sebanyak 607 ekor lahir dari jumlah populasi betina produktif sebanyak 2.440 sapi melalui program inseminasi buatan dengan tingkat persentase sebesar $44,63 \%$ sedangkan 753 ekor lahir melalu kawin alam dengan tingkat persentase sebesar 55,37\%. Melihat tingkat kelahiran tiap wilayah tersebut maka dapat disimpulkan dengan adanya inovasi Pelan Itu Bagus dapat menopang keberhasilan program inseminasi buatan yaitu menghasilkan 1 ekor sapi/tahun. Namun disisi 
Tabel 4. Pendapatan Peternak Berdasarkan Skala Usaha

\begin{tabular}{lcc}
\hline Skala Usaha (Ekor) & Jumlah Responden (orang) & Rata-rata Penerimaan Bersih (Rp) \\
\hline $3-7$ & 27 & 11.500 .000 \\
$8-12$ & 73 & 17.250 .000 \\
$13-17$ & 54 & 34.500 .000 \\
$18-22$ & 35 & 40.250 .000 \\
$23-27$ & 25 & 46.000 .000 \\
$28-32$ & 26 & 47.250 .000 \\
$33-37$ & 10 & 57.500 .000 \\
$38-42$ & 9 & 69.000 .000 \\
$43-47$ & 7 & 80.500 .000 \\
\hline
\end{tabular}

Sumber: Data primer, 2020.

lain, tingkat efektivitas penerapan teknologi inseminasi buatan belum maksimal dilihat dari kelahiran kawin alam masih lebih tinggi bila dibandingkan dengan lahir inseminasi buatan.

\section{Tingkat Penyakit Reproduksi}

Penyakit reproduksi adalah penyakit menular yang akan menghambat proses terjadinya kebutingan pada ternak sapi betina produktif sehingga dapat menjadi dampak terhadap efesiensi reproduksi ternak tersebut (Adjid, 2004).

Total kasus gangguan reproduksi sebanyak 68 kasus, hal ini menunjukkan bahwa secara keseluruan di wilayah Kabupaten Pinrang kasus gangrep tiap tahun di bawah 1 ekor/tahun (Tabel 3). Dengan demikian, dapa disimpulkan bahwa tujuan program Pelan itu Bagus tercapai dengan melihat penanganan kasus gangrep dapat di atasi. Berdasarkan data Isikhnas Dinas Peternakan dan Perkebunan (2019) jumlah kasus gangguan reproduksi sapi sebelum adanya inovasi Pelan Itu Bagus sebanyak 586 kasus dengan tingkat persentase $60,47 \%$ pada tahun 2017. Kemudian setelah adanya inovasi Pelan Itu Bagus jumlah kasus gangguan reproduksi menurun yaitu sebanyak 383 kasus dengan tingkat persentase 39,53\% pada tahun 2019. Program pelayan berkelanjutan inseminasi buatan dan gangguan reproduksi sapi nyata memberikan kontribusi terhadap penurunan jumlah kasus gangguan reproduksi yaitu sebesar 203 kasus atau 34,64\%. Adapun beberapa kasus gangguan reproduksi sapi yang terjadi di peternak-peternak yaitu Retensio Secundinarum, Pyometra, Hipofungsi ovari, dan Corpus Luteum Persisten. Lebih lanjut Luthfi dan Widyaningrum (2017) mengatakan bahwa kasus tertinggi gangguan reproduksi sapi adalah Distokia dan Abortus yang terjadi pada induk sapi pada umur 2 Tahun, selanjutnya kasus Retensio Secundinarum, Pyometra, Hipofungsi ovari, dan Corpus Luteum Persisten terjadi pada sapi yang berumur 3 sampai 5 Tahun. Berdasarkan data rekap recording program upsus siwab Kabupaten Pinrang menunjukkan Jumlah kasus gangguan reproduksi sapi yang terjadi, rata-rata menunjukkan status Sudah Baik (SB) atau sembuh.

\section{Pendapatan Peternak}

Pendapatan peternak merupakan selisi antara jumlah penerimaan dengan biaya yang dikeluarkan selama proses produksi (Anindyasari et al., 2015). Pada penelitian ini pendapatan diukur dari jumlah ternak lahir dalam satu tahun yang dilihat dari jumlah perbandingan betina produktif.

Jumlah pendapatan peternak tertinggi pada skala usaha 43 sampai 47 ekor sebesar Rp. $\quad 80.500 .000$ sedangkan pendapatan terendah pada skala usaha 3 sampai 7 ekor sebesar Rp. 11.500.000 (Tabel 4). Pendapatan 
dihitung berdasarkan hasil penjualan ternak tiap tahunnya. Dalam penelitian ini, peternak sapi potong mampu menjual 9 sampai 10 ekor untuk skala usaha tertinggi dan 1 sampai 2 ekor untuk skala terendah. Pendapatan peternak pada penelitian ini merupakan pendapatan bersih dari selisih antara jumlah penerimaan dengan biaya yang dikeluarkan selama proses produksi. Harga sapi potong hasil inseminasi buatan dan kawin alam sangat berbeda. Hasil inseminasi di badrol paling tinggi 35 juta per ekor dan paling rendah 7 juta per ekor. Pada penelitian ini, rata-rata peternak menjual pada umur 1 sampai 2 tahun dengan harga Rp. 14.500.000 sampai 19.500.000. Bila dibandingkan dengan harga sapi potong hasil kawin alam yang hanya mampu dijual dengan harga Rp. 8.000.000 sampai 14.000.000. Lebih lanjut, Oktavianus et al. (2020) menyatakan bahwa pendapatan ideal sapi program inseminasi buatan sebesar Rp. 17.369.096 dan sapi kawin alam sebesar Rp. 13.947.153.

\section{KESIMPULAN}

Berdasarkan hasil penelitian yang telah dilakukan maka dapat disimpulkan bahwa program Pelayanan Berkelanjutan Inseminasi Buatan dan gangguan Reproduksi Sapi (Pelan Itu Bagus) di Kabupaten Pinrang menunjukkan peningkatan pada pelayanan petugas. Pada tingkat kelahiran tujuan program Pelan Itu Bagus berhasil dengan melihat setiap peternak mampu menghasilkan 1 ekor/tahun, namun dalam penerapan teknologi inseminasi buatan belum efektif karena kelahiran kawin alam masih dominan dibandingkan dengan IB. Jumlah kasus gangguan reproduksi dapat menurun serta pendapatan peternak meningkat.

\section{DAFTAR PUSTAKA}

Adjid, A. R. M. 2004. Strategi Alternatif Pengendalian Penyakit Reproduksi Menular untuk Meningkatkan Efesiensi
Reproduksi Sapi Potong. Jurnal Wartazoa. 14(3): 125-132

Amin, N., M. Umbang., A. Rokhayanti, dan N. K. Laya. 2019. Peran Inseminasi Buatan (IB) Terhadap Sistem Perkawinan di Kelompok Tani Ternak Lembu Karomah Kecamatan Taluditi Kabupaten Pohuwato. Jambura Journal of Animal Science. 2(1).

Anidyasari, D., Setiadi, A., dan Ekowati, T. 2015. Analisis Pendapatan Peternak Sapi Perah di Kecamatan Banyumanik, Kecamatan Getasan, dan Kecamatan Cepogo. Jurnal Mediagro. 11(2): 22-33.

Armelia, V., Dadang, M. S., dan Novie, A. S. 2019. Idetifikasi Penyebab Gangguan Reproduksi Sapi Potong di Kabupaten Ogan Komering Ulu Timur Provinsi Sumatera Selatan Pada Program UPSUS SIWAB 2018. Journal Livestock and Animal Production. 2(1): 51-63

Dinas Peternakan dan Perkebunan. 2017. Inovasi Pelayanan Secara Berkelanjutan Inseminasi Buatan dan Gangguan Reproduksi Sapi.Pinrang: Disnakbun.

Direktorat Jenderal Peternakan dan Kesehatan Hewan. 2021. Statistik Peternakan dan Kesehatan Hewan. Livestock and Animal Health Statistic 2012. Jakarta: Direktorat Jenderal Peternakan dan Kesehatan Hewan. Kementerian Pertanian.

Luthfi, M. dan Widyaningrum, Y. 2017. TingkatKejadian Gangguan Reproduksi Sapi Bali dan Madura pada Sistem Pemeliharaan Kandang Kelompok. Prosiding Seminar Nasional Teknologi Peternakan dan Veteriner. 101-108.

Malik, A. 2019. Efek Penyuntikan Prostaglandin Terhadap Timbul dan Lama Birahi Sapi Bali Pada Paritas yang Berbeda. Ziraah'ah. 44(2):142146.

Oktavianus., C. M. Phun., Ronrimpandey, M. A. V., dan Manese, S. J. K. 2020. Perbandingan Pendapatan Antara Ternak Sapi Ongole yang Menggunakan 
IB dan Kawin Alam di Desa Tempok Kecamatan Tampaso. Zootec. 40(1): 324-335.

Prasojo, G., Arifiantini, I., dan Mohamad, K. 2010. Korelasi Antara Lama Kebuntingan, Bohot Lahir dan Jenis Kelamin Pedet Hasil Inseminasi Buatan pada Sapi Bali. Jurnal Veteriner, 11( 1):41-45.

Rusdiana, S. dan Soeharsono. 2018. Program
Siwab untuk Meningkatkan Populasi Sapi Potong dan Nilai Ekonomi Usaha Ternak. Forum Penelitian Agro Ekonomi. 35(2): 125-137.

Zakiah., A. Saleh, dan K. Matindas. 2017. Gaya Kepemimpinan dan Prilaku Komunikasi GPPT dengan Kapasitas Kelembagaan Sekolah Peternakan Rakyat di Kabupaten Muara Enim. Jurnal Penyuluhan. 13(2): 133-142 